\title{
Poly(3,4-ethylenedioxythiophene) Doped with Carbon Materials for High-Performance Supercapacitor: A Comparison Study
}

\author{
Shariffah Nur Jannah Syed Zainol Abidin,, ${ }^{1}$ Nur Hawa Nabilah Azman, \\ Shalini Kulandaivalu, ${ }^{1}$ and Yusran Sulaiman ${ }^{1,2}$ \\ ${ }^{1}$ Department of Chemistry, Faculty of Science, Universiti Putra Malaysia, 43400 Serdang, Selangor, Malaysia \\ ${ }^{2}$ Functional Device Laboratory, Institute of Advanced Technology, Universiti Putra Malaysia, 43400 Serdang, Selangor, Malaysia \\ Correspondence should be addressed to Yusran Sulaiman; yusran@upm.edu.my
}

Received 7 December 2016; Revised 3 February 2017; Accepted 22 February 2017; Published 12 March 2017

Academic Editor: Yanmei Piao

Copyright (C) 2017 Shariffah Nur Jannah Syed Zainol Abidin et al. This is an open access article distributed under the Creative Commons Attribution License, which permits unrestricted use, distribution, and reproduction in any medium, provided the original work is properly cited.

\begin{abstract}
A comparative study of multiwalled carbon nanotube (MWCNT), graphene oxide (GO), and nanocrystalline cellulose (NCC) as a dopant in the preparation of poly(3,4-ethylenedioxythiophene)- (PEDOT-) based hybrid nanocomposites was presented here. The hybrid nanocomposites were prepared via the electrochemical method in aqueous solution. The FTIR and Raman spectra confirmed the successful incorporation of dopants (MWCNT, GO, and NCC) into PEDOT matrix in the process of formation of the hybrid nanocomposites. It was observed that the choice of the carbon material affected the morphologies and supercapacitive properties of the hybrid nanocomposites. Incorporation of GO with PEDOT produces a paper-like sheet nanocomposite in which the wrinkled surface results in larger surface area compared to the network-like and rod-like structures of PEDOT/MWCNT and PEDOT/NCC, respectively. Owing to larger surface area, PEDOT/GO exhibits the highest specific capacitance (120.13 F/g), low equivalent series resistance $(34.44 \Omega$ ), and retaining $87.99 \%$ of the initial specific capacitance after 1000 cycles, signifying a long-term cycling stability. Furthermore, the high performance of PEDOT/GO is also demonstrated by its high specific energy and specific power.
\end{abstract}

\section{Introduction}

Nowadays, the evolving interest for high-performance energy storage and delivery systems has driven tremendous efforts towards the improvement of the supercapacitors. Supercapacitor, which is acknowledged as one of the essential energy storage devices of future, exhibits several important features. Compared to other energy storage devices, supercapacitor has displayed a large specific capacitance, higher power density, and longer life cycle $[1,2]$. Fundamentally, supercapacitors can be classified into two main groups based on their energy charge storage mechanism, that is, electrical double layer capacitors (EDLC) and pseudocapacitors. In an EDLC with carbon-based materials as an electrode material, the energy storage is derived electrostatically from the charging process [3]. In contrast, pseudocapacitor uses conducting polymers $(\mathrm{CP})$ or metal oxides as electrode materials stores charge via reversible Faradic reaction [4]. In recent times, extensive studies have been carried out to enhance the performance of supercapacitor by varying the electrode materials [5-7].

Among the available materials, carbon materials are an outstanding choice as an electrode material in a supercapacitor. Carbon plays its part in supercapacitor by maximizing the porosity and minimizing the interparticle contact resistance [8]. Recently, carbon materials such as functionalized multiwalled carbon nanotube (MWCNT), graphene oxide (GO), and nanocrystalline cellulose (NCC) have been focused intensively due to its excellent properties. MWCNT is known for its excellent mechanical strength, high conductivity, high chemical stability, and large surface area [9], whereas GO exhibits impressive mechanical, electrical, and thermal properties [10], while NCC which is derived from cellulose, it is naturally abundant, nontoxic, renewable, and biodegradable [11]. 


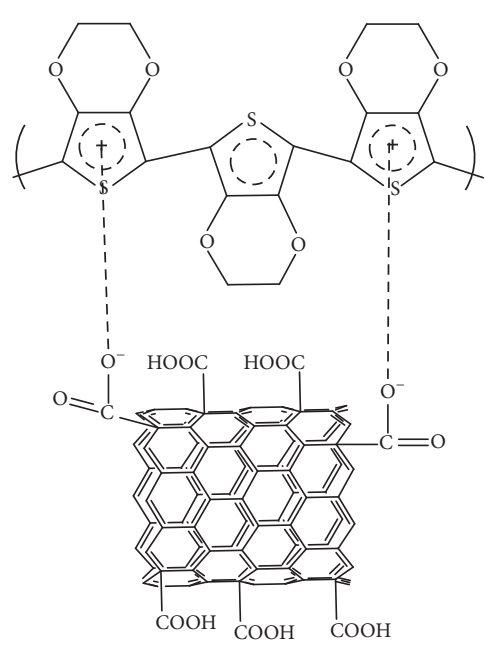

PEDOT/MWCNT

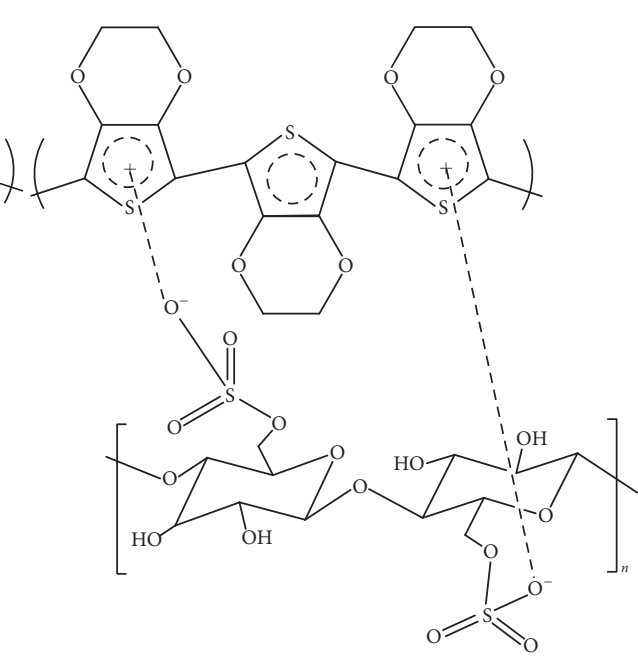

PEDOT/NCC

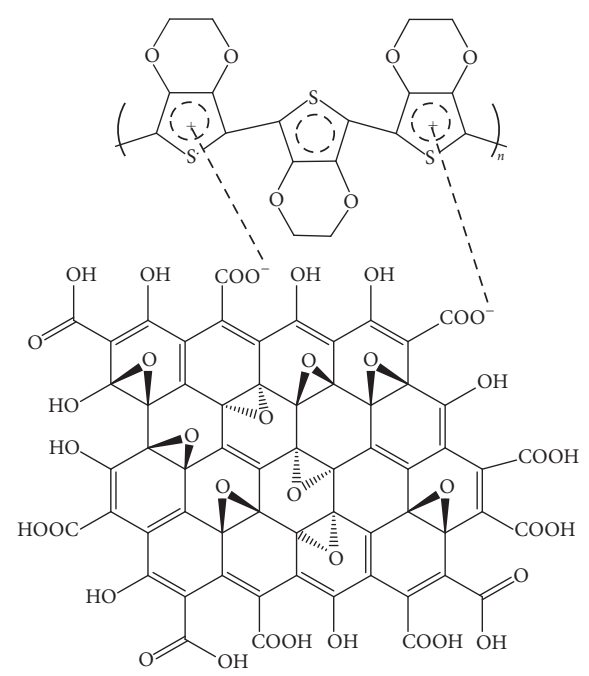

PEDOT/GO

FIGURE 1: Schematic diagram of PEDOT doped with different dopants.

Although carbon-carbon supercapacitor has high power density and good cycling stability, its energy density and specific capacitance are not satisfactory, thus limiting its application [12]. Therefore, a combination of carbon materials with $\mathrm{CP}$ is an alternative method to improve the properties of carbon material. Conducting polymers such as polyaniline, polythiophene, polyacetylene, polypyrrole, and poly(3,4-ethylenedioxythiophene) (PEDOT) are promising materials for polymer-based capacitors [13]. Among these conducting polymers, PEDOT is a good candidate for electrochemical studies due to its excellent conductivity [14]. However, PEDOT suffers from some drawbacks such as low capacity to store charge [15] and poor cycling stability [16]. These weaknesses have limited the potential application of PEDOT as an electrode material for supercapacitor. Therefore, considerable research attention has been concentrated on incorporating PEDOT with a conductive material such as carbon material to achieve high electrochemical performance materials. Han et al. [17] have demonstrated that PEDOT/GO nanocomposites doped with poly(sodium styrene sulfate) (PSS) fabricated via in situ polymerization had achieved a specific capacitance of $108 \mathrm{~F} / \mathrm{g}$, much higher than its individual constituents. Chen et al. [18] have reported coreshell PEDOT/PSS-MWCNTs nanocomposite prepared by in situ polymerization under a hydrothermal condition capable of reaching specific capacitance of $198.2 \mathrm{~F} / \mathrm{g}$. These studies mostly focused on modifying and improving the electrochemical performances of the resulting nanocomposites, and, so far, there is no comparison study that has been conducted on the supercapacitive performance of PEDOT doped with different dopants.

Therefore, in the present work, PEDOT doped with three different carbon materials, that is, MWCNT, GO, and NCC, (Figure 1) were prepared electrochemically under the same experimental conditions and the capacitive performance of these nanocomposites was evaluated and compared. The synergistic effect of the combination of these materials is believed to play a vital role in determining the supercapacitive performance.

\section{Experimental Section}

2.1. Chemicals and Reagents. 3,4-Ethylenedioxythiophene (EDOT) (stored in refrigerator at $2-4^{\circ} \mathrm{C}$ ) and MWCNT (length: $3-6 \mu \mathrm{m}$; diameter: $4.5 \pm 0.5 \mathrm{~nm}$ ) were obtained from Sigma-Aldrich. Sulfuric acid $\left(\mathrm{H}_{2} \mathrm{SO}_{4}\right)$ and concentrated nitric acid $\left(\mathrm{HNO}_{3}\right)$ were purchased from Friedemann Schmidt and Fischer Scientific, respectively. GO and NCC were purchased from Graphenea and the University of Maine, respectively. Potassium chloride $(\mathrm{KCl})$, acetone, and ethanol were obtained from Fisher Chemical, ChemAR ${ }^{\circledR}$, and $\mathrm{HmbG}^{\circledR}$, respectively. Deionized (DI) water from Millipore (Milli-Q, $18.2 \mathrm{M} \Omega \cdot \mathrm{cm}$ ) was used throughout the experiments.

2.2. Functionalization of $M W C N T$. MWCNTs were functionalized by acid treatment. The MWCNTs were pretreated by

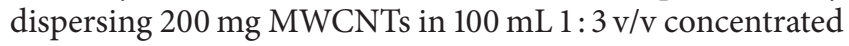
$\mathrm{HNO}_{3}$ solution and concentrated $\mathrm{H}_{2} \mathrm{SO}_{4}$ followed by sonication for 2 hours. The mixture was then kept overnight at room temperature. The resulting acidic mixture was washed several times using deionized water until the $\mathrm{pH}$ reached 7 . Functionalized MWCNTs were collected and dried at $60^{\circ} \mathrm{C}$.

\subsection{Electrodeposition. PEDOT/MWCNT, PEDOT/NCC,} and PEDOT/GO were electrodeposited onto indium tin oxide (ITO) glass at $1.2 \mathrm{~V}$ for $10 \mathrm{~min}$ using a potentiostat (Autolab M101) connected to a computer equipped with Nova 1.11 software. The concentration of EDOT used throughout the experiment was $10 \mathrm{mM}$ with $1.0 \mathrm{mg} / \mathrm{mL}$ of dopants (MWCNT, NCC, and GO). PEDOT was also prepared from a solution containing $\mathrm{LiClO}_{4}$ (noncarbon material) as a comparison. A conventional three-electrode system was employed with the ITO glass served as a working 


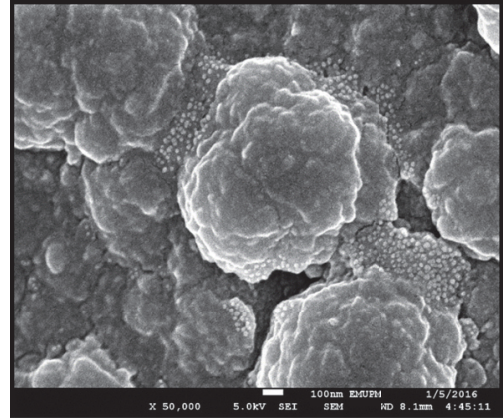

(a)

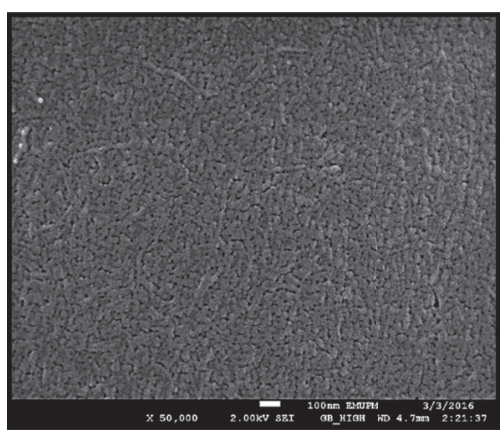

(d)

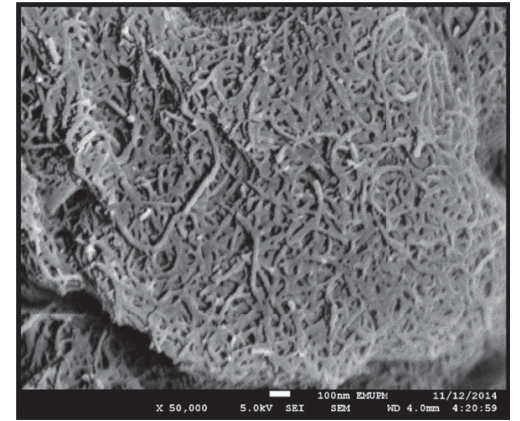

(b)

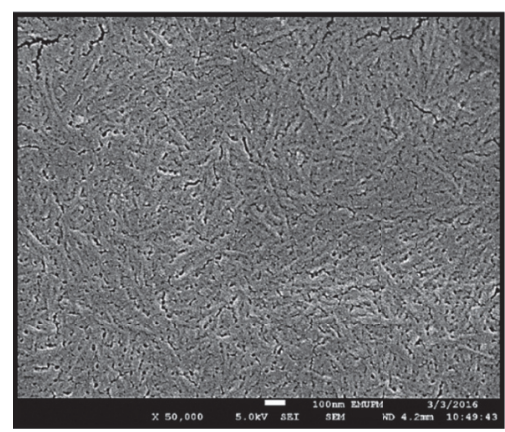

(e)

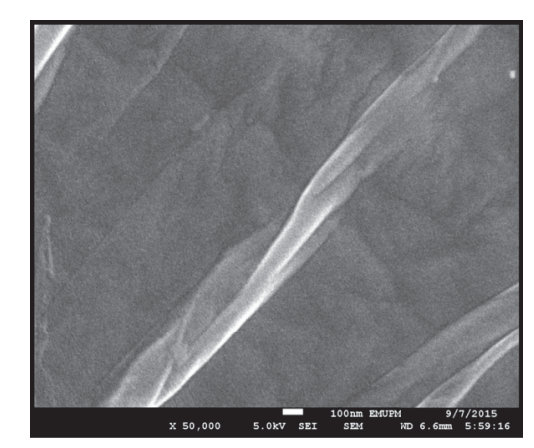

(g)

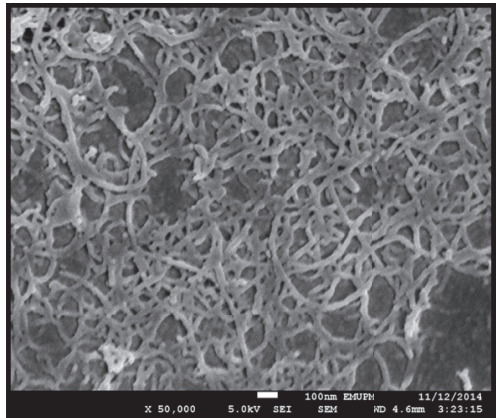

(c)

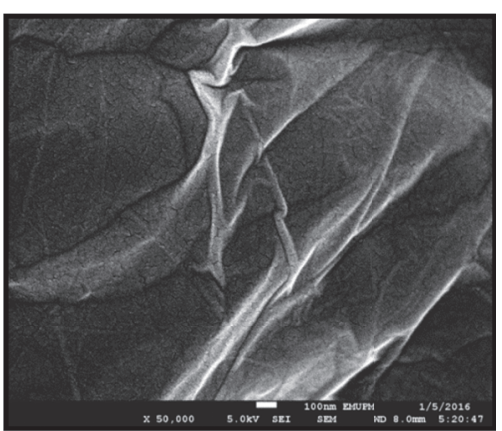

(f)

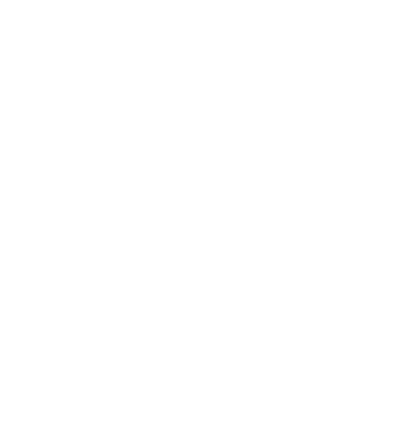


Based on Figure 2(c), PEDOT/MWCNT hybrid nanocomposite depicts entangled network-like structure in which MWCNT are well-dispersed within the hybrid nanocomposites. However, compared to MWCNT (diameter of 26.26.0 $\pm 0.1 \mathrm{~nm}$ (Figure 2b)), PEDOT/MWCNT nanocomposite has less compact stacking morphology indicating a strong interfacial coupling between MWCNT and thiophene ring of PEDOT, hindering the multiple stacking of MWCNT. The FESEM image of NCC shows agglomerated rod-like structure (Figure 2(d)) and has a well-ordered arrangement [19]. The PEDOT/NCC (Figure 2(e)) exhibits the same rodlike structure, but there is a more spacious void between the PEDOT/NCC structure for electrolyte transport which is not seen in the pristine NCC. In contrast to PEDOT/MWCNT and PEDOT/NCC nanocomposites, the FESEM image of PEDOT/GO (Figure 2(g)) reveals a uniform wrinkled surface that resembles paper-like sheet. This FESEM image is similar to the morphology of pristine GO; however, PEDOT/GO is less wrinkled compared to pristine GO. The combination of PEDOT with GO minimizes the entanglement and wrinkles during the deposition process. Morphologies of the hybrid nanocomposites and the respective dopant materials clearly indicate that MWCNT, NCC, and GO are dominating the structure of the hybrid nanocomposites.

3.2. Fourier Transform Infrared Spectroscopy. FTIR was performed in order to demonstrate the incorporation of GO, MWCNT, and NCC into PEDOT. The GO spectrum (Figure 3(b)) shows a broad $\mathrm{O}-\mathrm{H}$ absorption band centered at $3250 \mathrm{~cm}^{-1}$. The peaks at $1735,1368,1196$, and $1086 \mathrm{~cm}^{-1}$ are attributed to the $\mathrm{C}=\mathrm{O}$ carboxylic group, $\mathrm{C}-\mathrm{OH}$ deformation, $\mathrm{C}-\mathrm{O}-\mathrm{C}$, and $\mathrm{C}-\mathrm{O}$ epoxy, respectively. In the spectrum of MWCNT (Figure 3(d)), a broad peak that appears around $3400 \mathrm{~cm}^{-1}$ is assigned to the stretching mode of $\mathrm{O}-\mathrm{H}$ group, formed due to the oxidation of carbon on the surface of MWCNT [20]. The functional groups of $\mathrm{C}=\mathrm{O}, \mathrm{C}=\mathrm{C}, \mathrm{O}-\mathrm{H}$ bend, and $\mathrm{C}-\mathrm{O}$ are also found in the MWCNT spectrum at $1735,1528,1320$, and $1000 \mathrm{~cm}^{-1}$, respectively. As shown in Figure 3(f), the NCC spectrum consists of $\mathrm{O}-\mathrm{H}$, symmetric $\mathrm{CH}$ stretch sulfate group, $\mathrm{CH}_{2}$ bend, $\mathrm{H}-\mathrm{O}-\mathrm{H}$ bend, $\mathrm{OH}$ bend, $\mathrm{S}=\mathrm{O}, \mathrm{C}-\mathrm{O}-\mathrm{C}$, and $\mathrm{S}-\mathrm{O}$ where the absorption bands are present at $3500 \mathrm{~cm}^{-1}, 2931,1428,1637,1320,1184,1080$, and $819 \mathrm{~cm}^{-1}$, respectively.

Based on Figure 3(a), the main absorption bands of PEDOT are found below $1500 \mathrm{~cm}^{-1}$. FTIR spectrum of PEDOT shows peaks at $1543,1317,1196$, and $638 \mathrm{~cm}^{-1}$ corresponding to $\mathrm{C}=\mathrm{C}, \mathrm{C}-\mathrm{C}, \mathrm{C}-\mathrm{O}-\mathrm{C}$, and $\mathrm{C}-\mathrm{S}$ which are originated from the thiophene ring of PEDOT. The absorption bands of PEDOT can also be seen in the hybrid nanocomposite upon the addition of dopants into PEDOT indicating that the dopants and PEDOT were successfully incorporated together. The spectrum of PEDOT/GO (Figure 3(c)) consists of similar functional groups present in PEDOT with the addition of $\mathrm{C}=\mathrm{O}$ of the carboxylic group at $1735 \mathrm{~cm}^{-1}, \mathrm{C}$ $\mathrm{OH}$ deformation at $1368 \mathrm{~cm}^{-1}$, and $\mathrm{O}-\mathrm{H}$ peak in the range of $3300-3400 \mathrm{~cm}^{-1}$, which are originated from the GO. The IR absorption bands found in the PEDOT/MWCNT (Figure 3(e)) spectrum are also present in MWCNT spectrum.
Both PEDOT/MWCNT and MWCNT spectra consist of broad $\mathrm{O}-\mathrm{H}$ peak, $\mathrm{C}=\mathrm{O}, \mathrm{C}=\mathrm{C}, \mathrm{O}-\mathrm{H}$ bend, and $\mathrm{C}-\mathrm{O}$ at 3400 , $1735,1528,1320$, and $1000 \mathrm{~cm}^{-1}$, respectively. The functional groups of C-O-C and C-S present at 1196 and $638 \mathrm{~cm}^{-1}$ are originated from PEDOT. As can be seen in the spectra of PEDOT/GO (Figure 3(c)) and PEDOT/MWCNT (Figure 3(e)), the $\mathrm{O}-\mathrm{H}$ absorption peaks are shifted to the higher wavenumber compared to the spectra of GO (Figure 3(b)) and MWCNT (Figure 3(d)), indicating that the GO and MWCNT dopants were successfully incorporated into the PEDOT (Figure 1). Figure 3(f) demonstrates that the characteristic absorption bands of NCC appear at 3500, 2931, 1398, 1428,1184 , and $819 \mathrm{~cm}^{-1}$, suggesting the presence of NCC in the PEDOT/NCC nanocomposite. The FTIR results clearly show that the characteristic absorption bands of individual components and reveal the presence of GO, MWCNT, and NCC in the nanocomposites.

3.3. Raman Spectroscopy. Complementary to FTIR, Raman spectroscopy was employed to further study the structure of individual components and the hybrid nanocomposites. As can be seen in Figures 4(a) and 4(b), both Raman spectra of GO and MWCNT are comprised of G and D bands which appear at $1600 \mathrm{~cm}^{-1}$ and $1350 \mathrm{~cm}^{-1}$. The Dband explains the vibrations of carbon atoms with dangling bonds for the in-plane terminations of amorphous carbon films, whereas the $\mathrm{G}$ band describes the first-order scattering of $E_{2 \mathrm{~g}}$ mode [21]. $I_{\mathrm{D}} / I_{\mathrm{G}}$ is the intensity ratio of defect band which is used to indicate the degree of well-ordered graphitic structure [22]. The ratios of $I_{\mathrm{D}} / I_{\mathrm{G}}$ obtained for GO and MWCNT are 0.98 and 1.04, respectively, indicating that MWCNT is more defective than GO. The Raman spectrum of NCC (Figure 4(c)) illustrates the functional groups of scissors methylene stretch and $\mathrm{CH}_{2}$ bend present at 2820 and $1464 \mathrm{~cm}^{-1}$, respectively. The Raman spectrum of PEDOT (Figure $4(\mathrm{~d})$ ) consists of $\mathrm{C}=\mathrm{C}$ which appears at $1430 \mathrm{~cm}^{-1}$, whereas the presence of C-C thiophene ring, C-C, oxyethylene ring, and C-O-C deformation can be clearly seen at $1363,1265,985$, and $578 \mathrm{~cm}^{-1}$, respectively. From Figures 4(e) and 4(f), it can be clearly seen that the Raman bands of PEDOT/GO and PEDOT/MWCNT are almost similar to the Raman bands of PEDOT. The G and D bands of GO and MWCNT are almost overlapped with the strong Raman bands of PEDOT which makes the Raman bands of PEDOT/GO and PEDOT/MWCNT difficult to distinguish. Nevertheless, the existence of a small shoulder Raman band at $1600 \mathrm{~cm}^{-1}$ which is originated from GO and MWCNT was observed in the PEDOT/GO and PEDOT/MWCNT spectra, implying that the dopants have been successfully incorporated with PEDOT. Figure $4(\mathrm{~g})$ shows that the Raman spectrum of PEDOT/NCC is similar to PEDOT with the addition of $\mathrm{CH}_{2}$ bend at $1464 \mathrm{~cm}^{-1}$ and $\mathrm{CH}_{2}$ scissors at $2820 \mathrm{~cm}^{-1}$.

3.4. Cyclic Voltammetry. Cyclic voltammetry measurements were performed to investigate the capacitive performance of nanocomposites electrodes for supercapacitor. Figure 5(a) presents the cyclic voltammograms (CVs) of PEDOT/ 


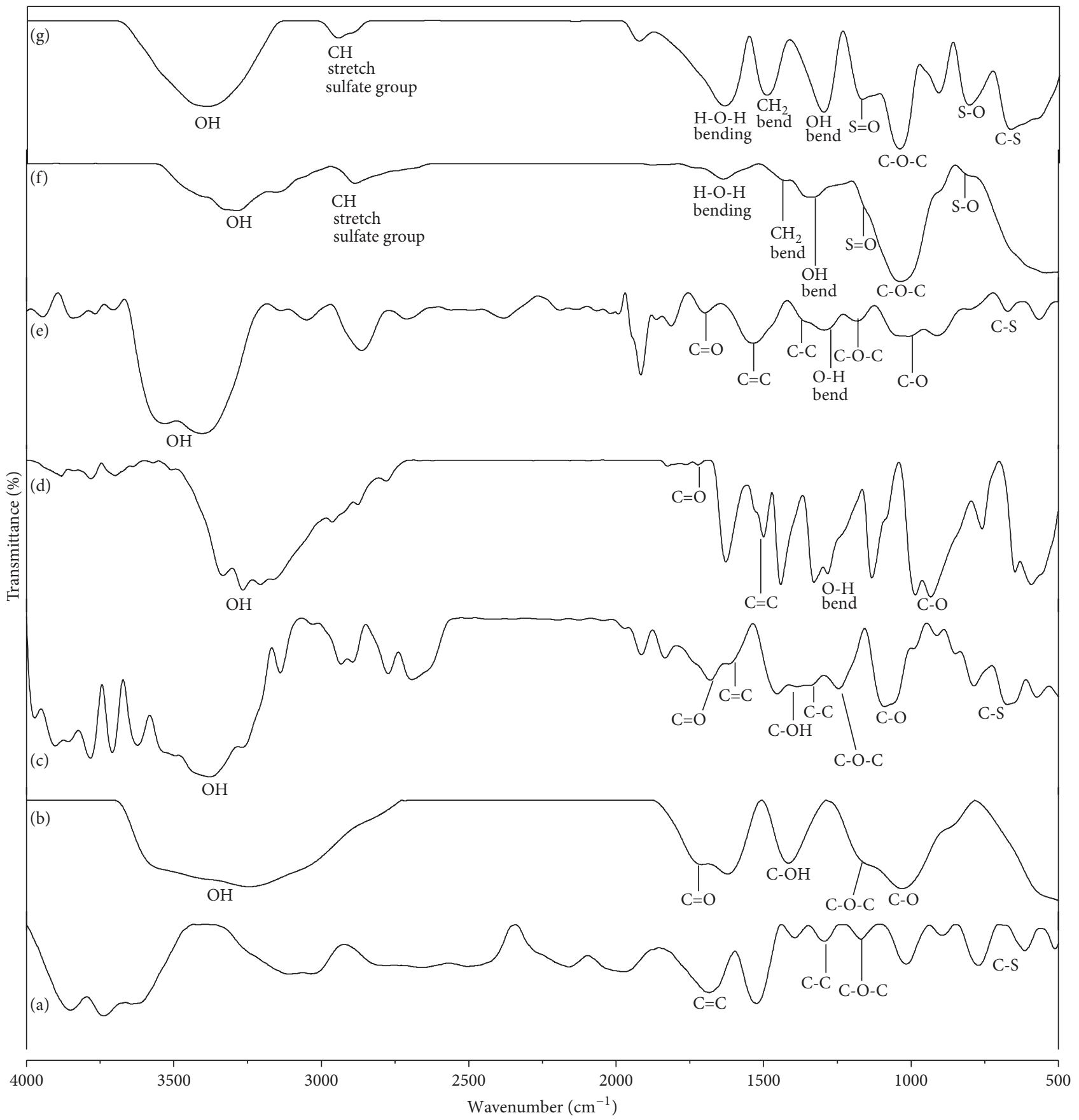

Figure 3: FTIR spectra of (a) PEDOT, (b) GO, (c) PEDOT/GO, (d) MWCNT, (e) PEDOT/MWCNT, (f) NCC, and (g) PEDOT/NCC.

MWCNT, PEDOT/NCC, and PEDOT/GO hybrid nanocomposites. The measurements were carried out using threeelectrode system at a scan rate of $0.1 \mathrm{~V} / \mathrm{s}$ in $1.0 \mathrm{M} \mathrm{KCl}$. As can be seen, the CVs of PEDOT/GO and PEDOT/NCC hybrid nanocomposites resemble a nearly rectangular and rectangular shape, respectively, implying good charge propagation and capacitive behavior [23]. In contrast, the CV of $\mathrm{PEDOT} / \mathrm{MWCNT}$ displays quasi-rectangular, demonstrating great double layer capacitance offered by MWCNT. The specific capacitance $\left(C_{\mathrm{sp}}\right)$ of the nanocomposites was calculated according to the following [5]:

$$
C_{\mathrm{sp}}=\frac{\int I d v}{v \Delta V m},
$$

where $C_{\mathrm{sp}}$ is the specific capacitance $\left(\mathrm{Fg}^{-1}\right), v$ is the potential scan rate $\left(\mathrm{Vs}^{-1}\right), I$ is the current response, $v$ is the scan rate $\left(\mathrm{Vs}^{-1}\right), \Delta V$ is the range of potential applied $(\mathrm{V})$, and 


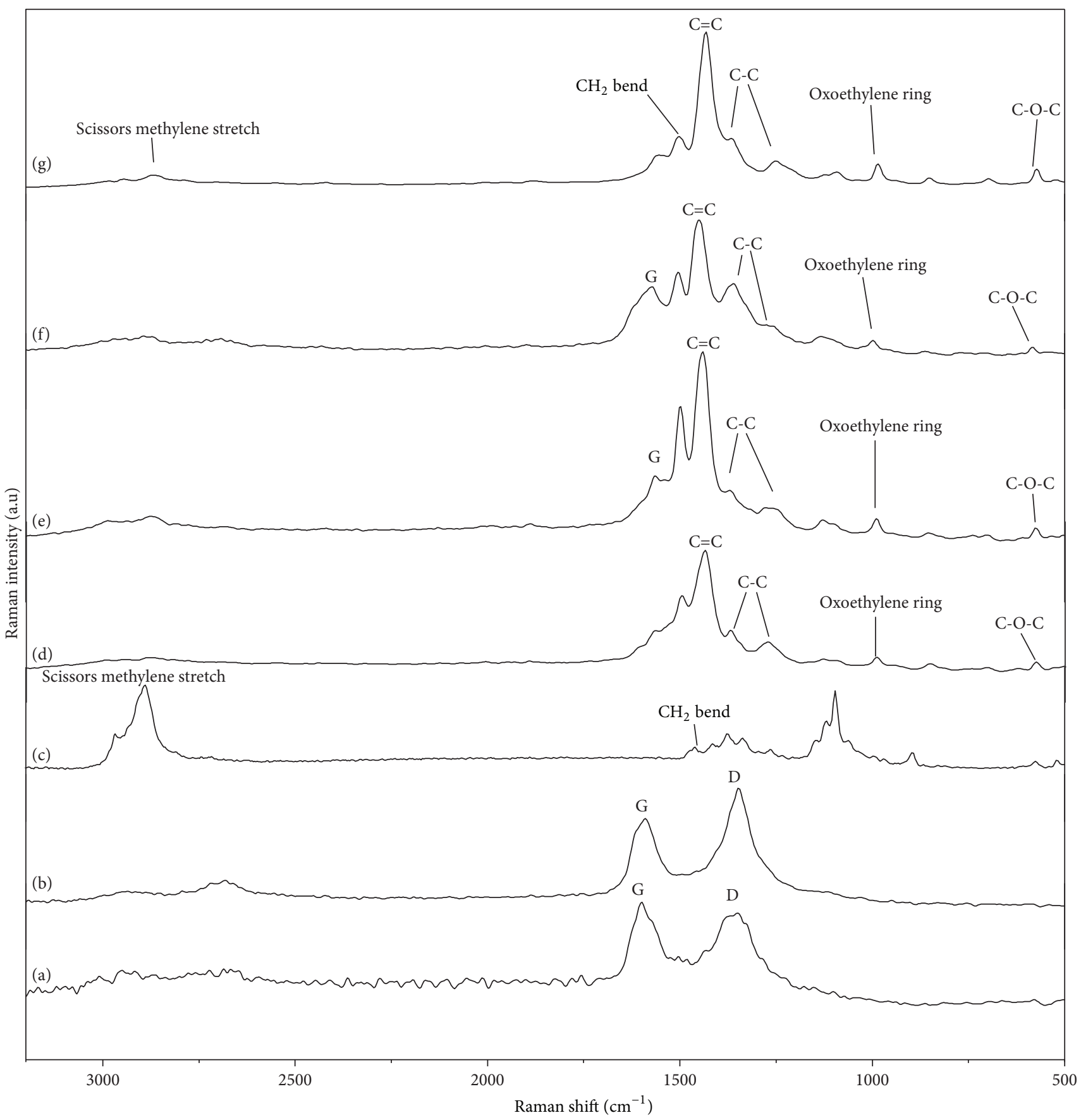

Figure 4: Raman spectra of (a) GO, (b) MWCNT, (c) NCC, (d) PEDOT, (e) PEDOT/GO, (f) PEDOT/MWCNT, and (g) PEDOT/NCC.

$m$ is the mass of the active materials $(\mathrm{g})$. It was observed that the CV integrated area of PEDOT/GO is larger compared to PEDOT/MWCNT and PEDOT/NCC, implying that PEDOT/GO nanocomposite has better capacitive behavior with specific capacitance of $120.13 \mathrm{~F} / \mathrm{g}$ (Figure 5(b)), while the PEDOT/MWCNT and PEDOT/NCC hybrid nanocomposites exhibit specific capacitance of $103.30 \mathrm{~F} / \mathrm{g}$ and $67.06 \mathrm{~F} / \mathrm{g}$, respectively. These results are comparable to the previous study on PEDOT-poly(styrene sulfonate)/single-walled carbon nanotube [24] and PEDOT/activated carbon [25]. The specific capacitance of PEDOT/GO is higher compared to PEDOT/MWCNT indicating that the rate of the electrochemical process that occurred in PEDOT/GO electrode is higher. The high rate of electrochemical process refers to the fast diffusion of counterion and electron in the PEDOT/GO matrix [26]. This could be due to the large surface area of GO compared to MWCNT [27]. The specific capacitance of PEDOT/MWCNT is higher compared to PEDOT/NCC which is maybe due to the open network morphology and unique property of the entangled nanotubes of CNT 

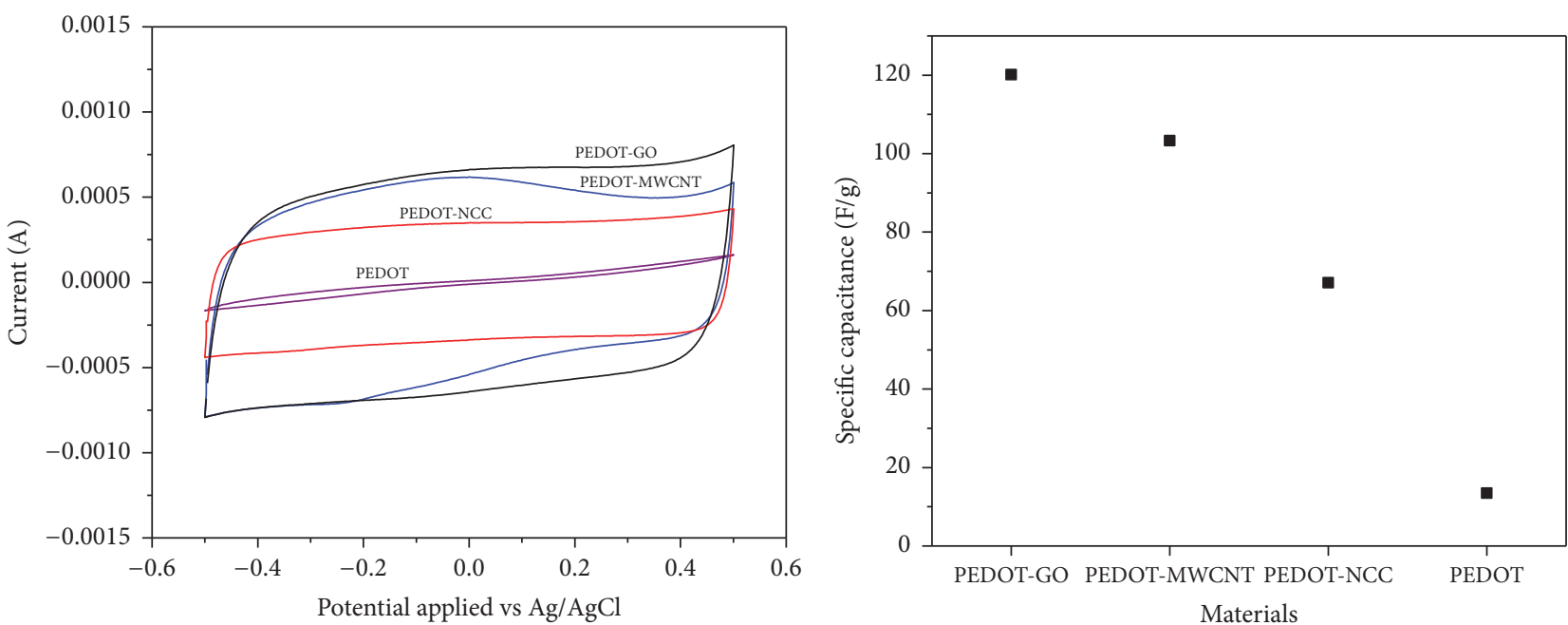

(a)

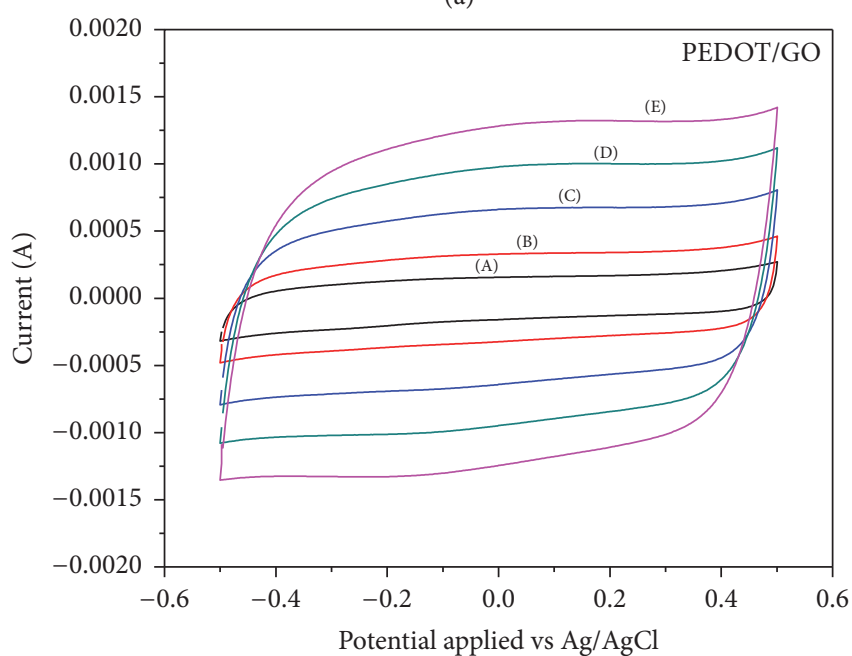

(b)

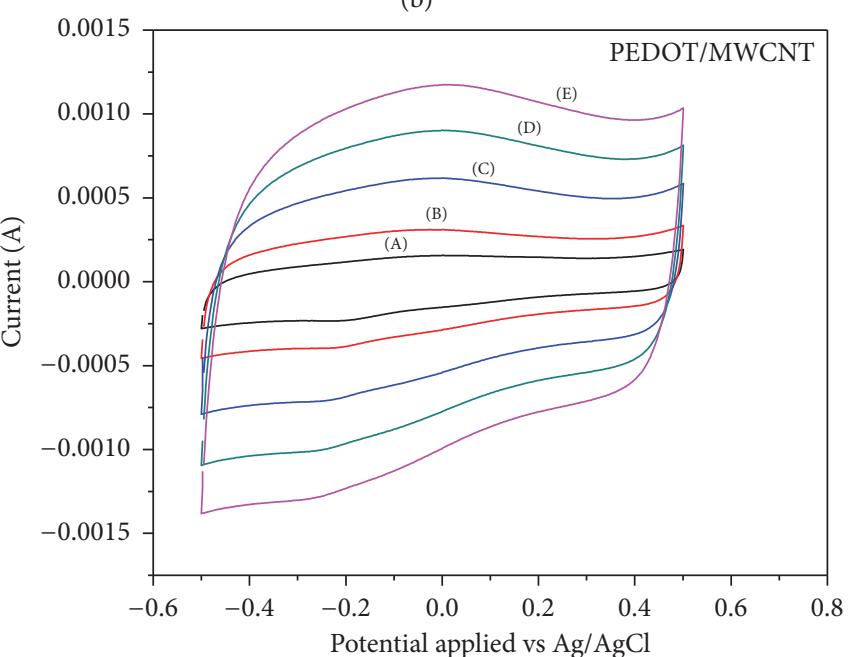
- (A) $25 \mathrm{mV} / \mathrm{s}$
- (D) $150 \mathrm{mV} / \mathrm{s}$
(B) $50 \mathrm{mV} / \mathrm{s}$
(E) $200 \mathrm{mV} / \mathrm{s}$

- (A) $25 \mathrm{mV} / \mathrm{s}$

- (D) $150 \mathrm{mV} / \mathrm{s}$

- (C) $100 \mathrm{mV} / \mathrm{s}$

- (B) $50 \mathrm{mV} / \mathrm{s}$

- (C) $100 \mathrm{mV} / \mathrm{s}$

(c)

(d)

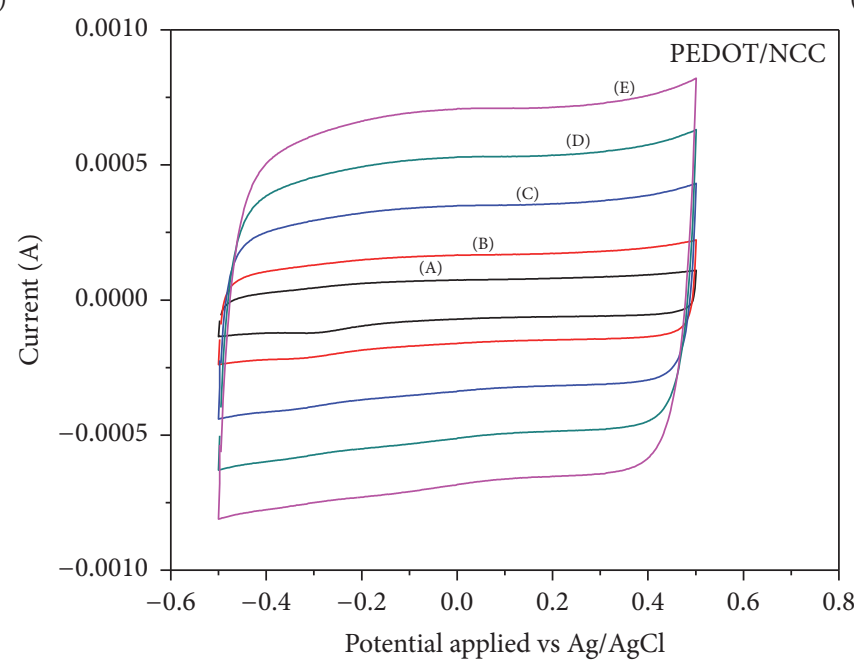
- (A) $25 \mathrm{mV} / \mathrm{s}$
(D) $150 \mathrm{mV} / \mathrm{s}$
- (B) $50 \mathrm{mV} / \mathrm{s}$
- (E) $200 \mathrm{mV} / \mathrm{s}$
_ (C) $100 \mathrm{mV} / \mathrm{s}$

(e)

FIGURE 5: (a) CV at $100 \mathrm{mV} / \mathrm{s}$ and (b) specific capacitance values. (c-e) CVs at different scan rates of PEDOT/GO, PEDOT/MWCNT, and PEDOT/NCC. 


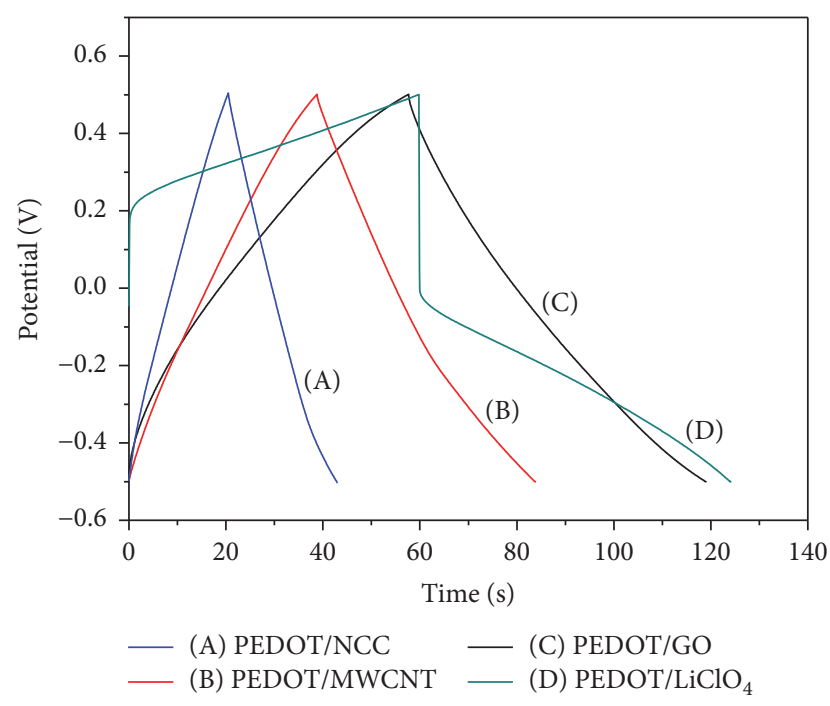

(a)

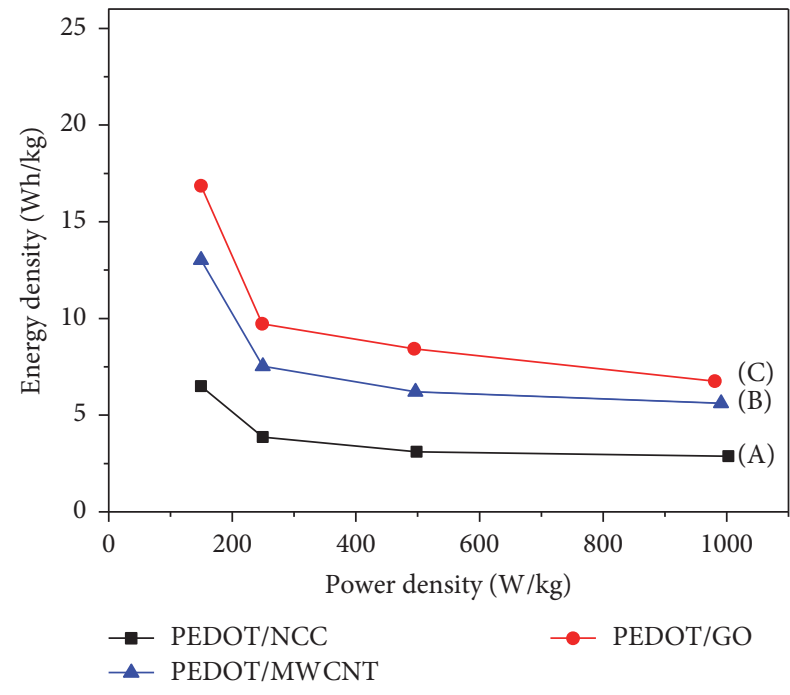

(b)

FIGURE 6: (a) Galvanostatic charge-discharge curves at 1.0 A/g current density and (b) Ragone plots.

which provides easy accessibility at the electrode/electrolyte interface that allows fast charge propagation and efficient reversible energy storage $[28,29]$. In contrast, PEDOT/NCC shows the lowest specific capacitance caused by insulating properties of NCC [30] and the agglomerated morphology of PEDOT/NCC as can be seen in the FESEM image, leading to poor utilization of the redox active sites and depreciation of specific capacitance [31]. The specific capacitances of the hybrid nanocomposites were compared with PEDOT electrodeposited in a solution containing $\mathrm{LiClO}_{4}$. From the $\mathrm{CV}$, the integrated area of PEDOT is smaller compared to PEDOT hybrid nanocomposites with a specific capacitance of $13.44 \mathrm{~F} / \mathrm{g}$, indicating that introducing carbon materials as dopants can increase the supercapacitive performance of the hybrid composites.

Cyclic voltammetry measurements at different scan rates, that is, $25,50,100,150$, and $200 \mathrm{mV} / \mathrm{s}$, were also employed in order to investigate the effect of different scan rate on the hybrid nanocomposites. It can be seen that the hybrid nanocomposites are still able to maintain the shapes even at high scan rates (Figures 5(c)-5(e)), suggesting good capacitance behavior and low contact resistance. The results manifest that the ionic diffusion is not limited by the scan rates, but it is influenced by the morphology of the hybrid nanocomposites.

3.5. Galvanostatic Charge-Discharge. In order to get more information on capacitive performances, galvanostatic charge/discharge (GCD) measurements were performed on the prepared hybrid nanocomposites. Figure 6(a) shows the GCD curves of PEDOT/LiClO 4 , PEDOT/NCC, $\mathrm{PEDOT} / \mathrm{MWCNT}$, and PEDOT/GO at a current density of $1.0 \mathrm{Ag}^{-1}$. As it can be seen, all the GCD curves for hybrid nanocomposites depict charging curve that is nearly symmetrical with their respective discharging curve without an obvious ohmic drop (IR drop). This feature indicates a good capacitive behavior, fast charge-discharge behavior [32] of PEDOT/NCC, PEDOT/MWCNT, and PEDOT/GO hybrid nanocomposites. It is clearly seen that PEDOT/GO has the longest charge-discharge time compared to other hybrid nanocomposite implying high specific capacitance [33] and good charge storage performance [34]. However, it should be pointed out that GCD curve of PEDOT/LiClO is not linear or symmetrical with large IR drop at the initial portion of discharge curve indicating that $\mathrm{PEDOT} / \mathrm{LiClO}_{4}$ has high internal resistance [35]. Thus, this signifies that the carbon material can improve the performance of PEDOT which also further confirmed by electrochemical impedance spectroscopy (EIS), which will be discussed in the following section.

Capacitive performances of these nanocomposites were further investigated by calculating the specific energy and specific power from charge-discharge curves at different current densities. The relationship between specific power and specific energy is expressed by using Ragone plot (Figure 6(b)). The specific power, $P$, and specific energy, $E$, were calculated according to the following equations:

$$
\begin{aligned}
& P=\frac{\Delta V \times I}{2 m}, \\
& E=\frac{C_{\mathrm{sp}} \times \Delta V^{2}}{2},
\end{aligned}
$$

where $\Delta V$ is voltage differences $(\mathrm{V}), I$ is applied current (A), $C_{\text {sp }}$ is specific capacitance $(\mathrm{F} / \mathrm{g})$, and $m$ is mass of hybrid nanocomposites films (g). As illustrated in the Ragone plot (Figure 6(b)), it is clearly seen that PEDOT/GO hybrid nanocomposites display higher specific energy compared with other hybrid nanocomposites. The plot indicates that PEDOT/GO is able to deliver a specific energy at a high point of $16.86 \mathrm{Wh} / \mathrm{kg}$ with a power density of $149.36 \mathrm{~W} / \mathrm{kg}$ and it is noticeable that the specific energy of PEDOT/GO 


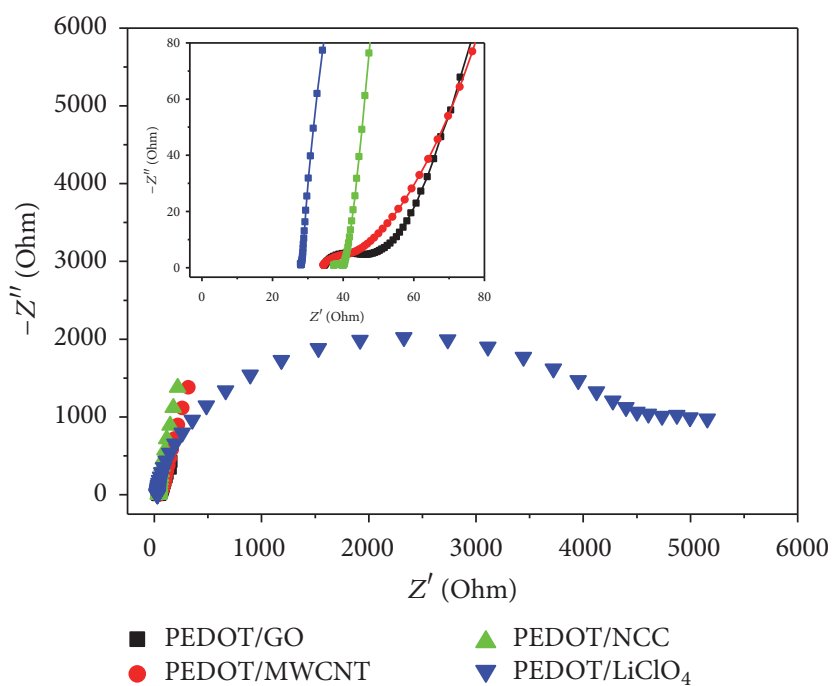

(a)

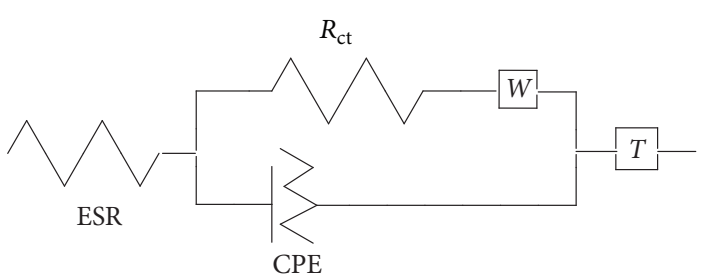

(b)

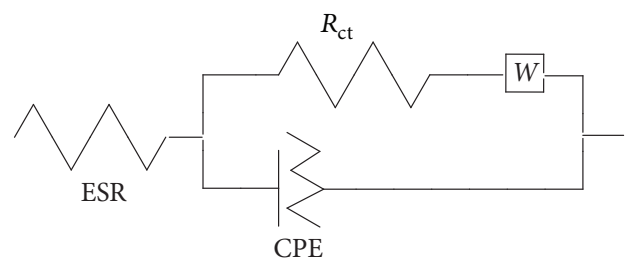

(c)

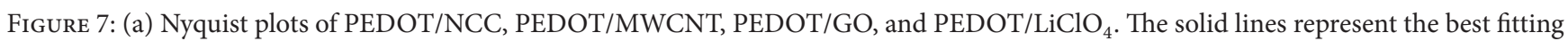
results in accordance with the equivalent circuits. Equivalent circuit for (b) PEDOT/GO and (c) PEDOT/NCC and PEDOT/MWCNT.

TABle 1: ESR and $R_{\mathrm{ct}}$ values for PEDOT/LiClO 4 , PEDOT/GO, PEDOT/MWCNT, and PEDOT/NCC.

\begin{tabular}{lcccc}
\hline & PEDOT/LiClO & PEDOT/GO & PEDOT/MWCNT & PEDOT/NCC \\
\hline $\operatorname{ESR}(\Omega)$ & 28.00 & 34.44 & 33.88 & 38.07 \\
$R_{\mathrm{ct}}(\Omega)$ & $4.22 \mathrm{k}$ & 13.51 & 15.85 & 9.63 \\
$\chi^{2}\left(10^{-2}\right)$ & 0.95 & 1.12 & 0.23 & 0.74 \\
\hline
\end{tabular}

still reached $6.77 \mathrm{Wh} / \mathrm{kg}$ at a power density of $980.84 \mathrm{~W} / \mathrm{kg}$. This performance of PEDOT/GO is superior compared to the other hybrid nanocomposites, PEDOT/MWCNT (13.09 Wh/kg at $149.62 \mathrm{~W} / \mathrm{kg})$ and PEDOT/NCC $(6.5 \mathrm{Wh} / \mathrm{kg}$ at $149.69 \mathrm{~W} / \mathrm{kg}$ ) implying that PEDOT/GO would be a more promising electrode material for supercapacitor due to high energy density and power density.

3.6. Electrochemical Impedance Spectroscopy. Electrochemical impedance spectroscopy (EIS) measurements were conducted to study the ion diffusion and charge transfer behavior of the hybrid nanocomposites. The impedance data of PEDOT/NCC, PEDOT/MWCNT, and PEDOT/GO in $1.0 \mathrm{M} \mathrm{KCl}$ solution are expressed in the form of Nyquist plots and depicted in Figure 7(a). All the Nyquist plots show similar pattern, that is, a semicircle at high-frequency region and a straight line at the low-frequency region. The diameter of the arc represents the charge transfer resistance (interface resistance) and the line shows the Warburg behavior which is resulted from ion diffusion to the electrode surface [36]. Obviously, among the hybrid nanocomposites, PEDOT/GO has shorter Warburg line than PEDOT/NCC and PEDOT/MWCNT implying that PEDOT/GO has fast and efficient ion movement from the electrolyte to the material surface [37]. However, as can be seen clearly in the Nyquist plot, the Warburg slope of PEDOT/NCC is approaching $90^{\circ}$ along the imaginary axis, a more vertical slope compared with other hybrid nanocomposites, implying good capacitor behavior, which is in agreement with the CV measurements.

Each of the Nyquist plots was analyzed using the equivalent circuit displayed in the Figures 7(b) and 7(c) and parameters extracted from Nyquist plot are tabulated in Table 1. The accuracy of fitted data was determined based on chi-square $\left(\chi^{2}\right)$ and the value of the present work is minimized to $10^{-2}$, indicating good fitting. The equivalent 
circuit consists of series of components which include the resistance of solution $\left(R_{s}\right)$, charge transfer resistance $\left(R_{p}\right)$, constant phase element (CPE), the "classical" finite-length Warburg diffusion element $(W)$, and hyperbolic tangent $(T)$. As can be observed from the FESEM images in Figure 2, the surface of hybrid nanocomposites is not homogenous with irregular geometries. Thus, $\mathrm{CPE}$ is included into the circuits substituting the double layer capacitance [38].

In the high-frequency region, the intercept point at the impedance spectra towards the real axis represents the equivalent series resistance (ESR). ESR value represents the resistance of the bulk electrolyte, the contact resistance between the electrode and current collector, and intrinsic resistance of hybrid nanocomposites [39]. Additionally, it is worth noting that the low value of ESR indicates high conductivity of the material [40]. The ESR value for PEDOT/NCC is $38.07 \Omega$, much higher than PEDOT/GO (34.44 $\Omega$ ) and PEDOT/MWCNT ( $33.88 \Omega$ ), demonstrating the weak electronic conduction of NCC structure compared to GO and MWCNT. As seen from Table 1, the differences in ESR values and $R_{\mathrm{ct}}$ values between PEDOT/GO and PEDOT/MWCNT are very small. These results prove that the behavior of PEDOT/GO and PEDOT/MWCNT does not vary much.

In addition, even though PEDOT/NCC exhibits the highest ESR value, the $R_{\mathrm{ct}}$ value is $9.63 \Omega$, which the lowest value recorded for hybrid nanocomposites in this study. The functionalization of NCC by substituting the hydroxide group with sulfate ester occurs at the $s p^{3}$ carbon atoms (Figure 1), whereas, in GO and MWCNT, the functionalization occurs at the $s p^{2}$ carbon atoms. Thus, the conjugated structures of GO and MWCNT are disrupted causing the hindrance for transport of electrons. Therefore, $R_{\mathrm{ct}}$ of PEDOT/GO and PEDOT/MWCNT nanocomposites is higher than that of PEDOT/NCC. In contrast to GO and MWCNT, there is no change in the aromatic structure of the NCC which enables the ease of electron transport. It is found that PEDOT/LiClO shows the lowest ESR value of $28.0 \Omega$ which is the result of good contact resistance between the electrode and current collector. The poor charge transfer between the electrolyte and PEDOT/ $/ \mathrm{LiClO}_{4}$ gives large $R_{\mathrm{ct}}$ value which is due to its globular microstructure, whereas the PEDOT doped with carbon materials have nanostructure which enhances the electron transport. In addition, it is worth noticing that the PEDOT doped with carbon material nanocomposites showed excellent charge transfer as a result of excellent synergistic contribution from the carbon material and PEDOT.

3.7. Stability Test. Figure 8 shows the cycle stability of all hybrid nanocomposites using $\mathrm{CV}$ at a scan rate of $0.1 \mathrm{~V} / \mathrm{s}$ for 1000 cycles. The excellent mechanical strength of dopant materials can help to improve the properties of conducting polymer and increase the stability performance of the nanocomposites. It was observed that there is a drastic drop in first 100 cycles (Figure 8) which is expected due to the continuous insertion and removal of counterions and charge carriers during the cycling [41]. After 1000 cycles, the specific capacitance of PEDOT/MWCNT shows a major loss in specific capacitance with retention of $64.42 \%$

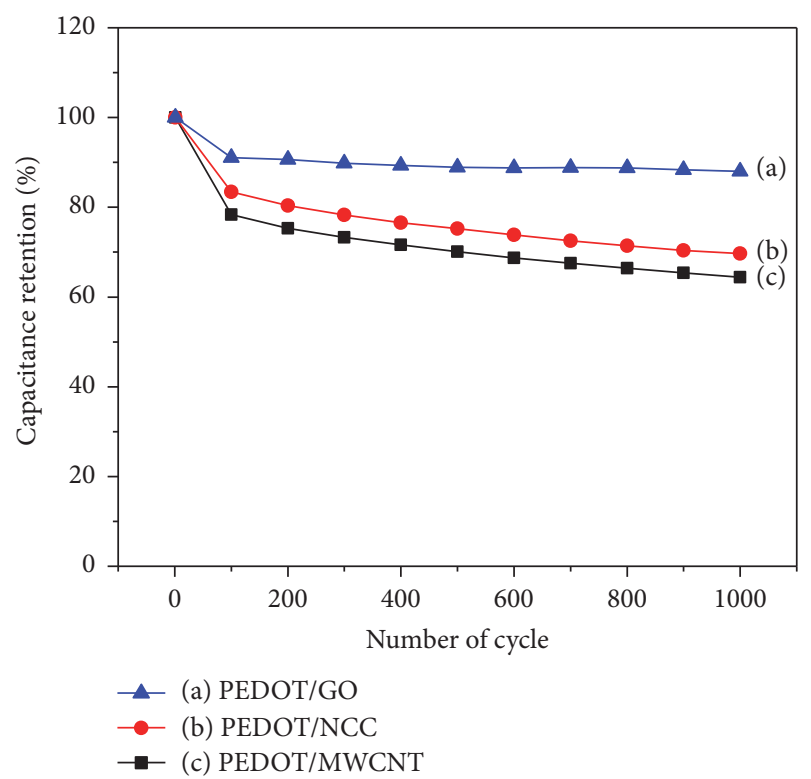

Figure 8: Stability test of (a) PEDOT/GO, (b) PEDOT/MWCNT, and (c) PEDOT/NCC hybrid nanocomposites.

in comparison to PEDOT/GO (87.99\%) and PEDOT/NCC (69.67\%). This behavior indicates that PEDOT/MWCNT has the poorest cycling performance due to the chain defects in the hybrid nanocomposite during the cycling which affect the mechanical stability of the hybrid nanocomposite [42]. As can be seen in the FESEM images (Figure 9), PEDOT is hardly noticeable in the hybrid nanocomposites after 1000 cycles signifying that PEDOT has been degraded and resulted in low capacitance retention. This study indicates that GO as a dopant has better mechanical strength compared to NCC and MWCNT that can overcome the swelling and shrinking [28] of PEDOT during the doping-dedoping process, subsequently improving the stability of PEDOT. The obtained hybrid nanocomposite shows good electrochemical properties and cycling stability indicating a synergistic effect of PEDOT and its respective dopants. Taking into account the high performance of PEDOT/GO such as high specific energy and specific power, PEDOT/GO stands as a good electrode material for supercapacitor.

\section{Conclusion}

Hybrid nanocomposites of PEDOT doped with GO, MWCNT, and NCC were successfully prepared using a facile potentiostatic method. The synergistic effect provided by both PEDOT and its respective dopants resulting in variation of morphologies which affect the supercapacitive performance of the hybrid nanocomposite. Compared to other carbon materials, incorporation of PEDOT with GO shows the highest specific capacitance $(120.13 \mathrm{~F} / \mathrm{g})$ and excellent stability retention (87.99\%) due to the higher mechanical strength and larger surface area provided by GO. Thus, PEDOT/GO hybrid nanocomposite is a promising 


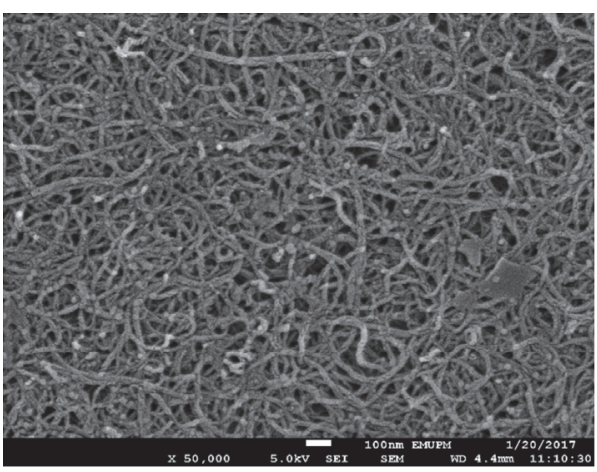

(a)

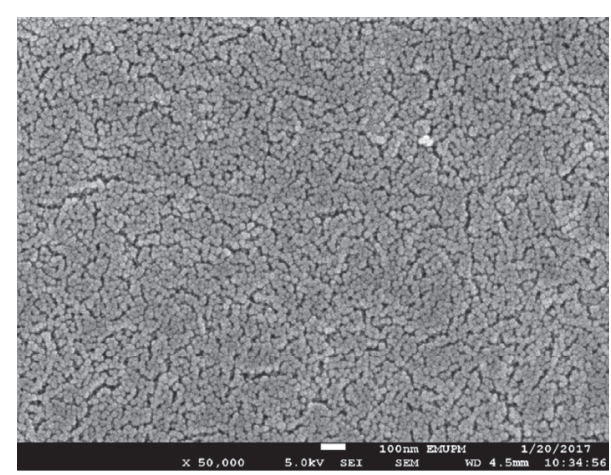

(b)

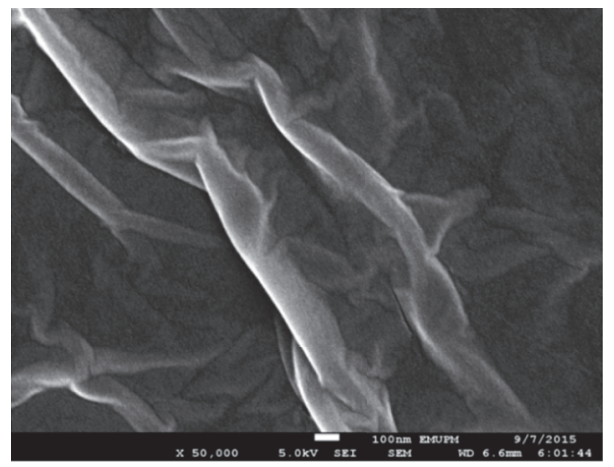

(c)

Figure 9: FESEM micrographs of (a) PEDOT/MWCNT, (b) PEDOT/NCC, and (c) PEDOT/GO after 1000 cycles.

candidate as an electrode material for high-performance supercapacitor.

\section{Conflicts of Interest}

The authors declare that there are no conflicts of interest regarding the publication of this paper.

\section{Acknowledgments}

This work was financially supported by Fundamental Research Grant Scheme (01-02-13-1388FR) from the Ministry of Education Malaysia and Science Fund (03-01-04-SF2044) from the Ministry of Science, Technology and Innovation (MOSTI).

\section{References}

[1] L. L. Zhang and X. S. Zhao, "Carbon-based materials as supercapacitor electrodes," Chemical Society Reviews, vol. 38, no. 9, pp. 2520-2531, 2009.

[2] S.-M. Chen, R. Ramachandran, V. Mani, and R. Saraswathi, "Recent advancements in electrode materials for the highperformance electrochemical supercapacitors: a review," International Journal of Electrochemical Science, vol. 9, no. 8, pp. 4072-4085, 2014.

[3] H. Zhou, G. Han, D. Fu, Y. Chang, Y. Xiao, and H.-J. Zhai, "Petal-shaped poly(3,4-ethylenedioxythiophene)/sodium dodecyl sulfate-graphene oxide intercalation composites for high-performance electrochemical energy storage," Journal of Power Sources, vol. 272, pp. 203-210, 2014.

[4] O. Movil, C. Schadeck, and J. A. Staser, "Investigation of doublelayer and pseudocapacitance of surface-modified ionic liquidfunctionalized graphene oxide," Journal of Electroanalytical Chemistry, vol. 755, pp. 127-135, 2015.

[5] P. Tang, L. Han, and L. Zhang, "Facile synthesis of graphite/ PEDOT/MnO2 composites on commercial supercapacitor separator membranes as flexible and high-performance supercapacitor electrodes," ACS Applied Materials and Interfaces, vol. 6, no. 13, pp. 10506-10515, 2014.

[6] C. Liu, Z. Yu, D. Neff, A. Zhamu, and B. Z. Jang, "Graphenebased supercapacitor with an ultrahigh energy density," Nano Letters, vol. 10, no. 12, pp. 4863-4868, 2010.

[7] V. Sahu, S. Shekhar, R. K. Sharma, and G. Singh, "Ultrahigh performance supercapacitor from lacey reduced graphene oxide nanoribbons," ACS Applied Materials and Interfaces, vol. 7, no. 5, pp. 3110-3116, 2015.

[8] A. G. Pandolfo and A. F. Hollenkamp, "Carbon properties and their role in supercapacitors," Journal of Power Sources, vol. 157, no. 1, pp. 11-27, 2006.

[9] X. Lu, W. Zhang, C. Wang, T.-C. Wen, and Y. Wei, "Onedimensional conducting polymer nanocomposites: synthesis, properties and applications," Progress in Polymer Science, vol. 36, no. 5, pp. 671-712, 2011.

[10] L. Zhang, R. Jamal, Q. Zhao, M. Wang, and T. Abdiryim, "Preparation of PEDOT/GO, PEDOT/MnO 2 , and PEDOT/GO/MnO nanocomposites and their application in catalytic degradation of methylene blue," Nanoscale Research Letters, vol. 10, no. 1, pp. $1-9,2015$. 
[11] L. Peponi, D. Puglia, L. Torre, L. Valentini, and J. M. Kenny, "Processing of nanostructured polymers and advanced polymeric based nanocomposites," Materials Science and Engineering R: Reports, vol. 85, no. 1, pp. 1-46, 2014.

[12] Q. Wang, J. Yan, and Z. Fan, "Carbon materials for high volumetric performance supercapacitors: design, progress, challenges and opportunities," Energy and Environmental Science, vol. 9, no. 3, pp. 729-762, 2016.

[13] G. A. Snook, P. Kao, and A. S. Best, "Conducting-polymerbased supercapacitor devices and electrodes," Journal of Power Sources, vol. 196, no. 1, pp. 1-12, 2011.

[14] E. Eren, G. Celik, A. Uygun, J. Tabačiarová, and M. Omastová, "Synthesis of poly(3,4-ethylenedioxythiophene)/titanium dioxide nanocomposites in the presence of surfactants and their properties," Synthetic Metals, vol. 162, no. 15-16, pp. 1451-1458, 2012.

[15] G. M. Suppes, B. A. Deore, and M. S. Freund, "Porous conducting polymer/heteropolyoxometalate hybrid material for electrochemical supercapacitor applications," Langmuir, vol. 24, no. 3, pp. 1064-1069, 2008.

[16] W. Yang, Y. Zhao, X. He et al., "Flexible conducting polymer/reduced graphene oxide films: synthesis, characterization, and electrochemical performance," Nanoscale Research Letters, vol. 10, no. 1, article no. 222, 2015.

[17] Y. Han, B. Ding, H. Tong, and X. Zhang, "Capacitance properties of graphite oxide/poly(3,4-ethylene dioxythiophene) composites," Journal of Applied Polymer Science, vol. 121, no. 2, pp. 892-898, 2011.

[18] L. Chen, C. Yuan, H. Dou, B. Gao, S. Chen, and X. Zhang, "Synthesis and electrochemical capacitance of core-shell poly (3,4-ethylenedioxythiophene)/poly (sodium 4-styrenesulfonate)-modified multiwalled carbon nanotube nanocomposites," Electrochimica Acta, vol. 54, no. 8, pp. 2335-2341, 2009.

[19] J.-S. Fan and Y.-H. Li, "Maximizing the yield of nanocrystalline cellulose from cotton pulp fiber," Carbohydrate Polymers, vol. 88, no. 4, pp. 1184-1188, 2012.

[20] M. A. Atieh, O. Y. Bakather, B. Al-Tawbini, A. A. Bukhari, F. A. Abuilaiwi, and M. B. Fettouhi, "Effect of carboxylic functional group functionalized on carbon nanotubes surface on the removal of lead from water," Bioinorganic Chemistry and Applications, vol. 2010, Article ID 603978, 9 pages, 2010.

[21] A. K. Sarker and J.-D. Hong, "Electrochemical reduction of ultrathin graphene oxide/polyaniline films for supercapacitor electrodes with a high specific capacitance," Colloids and Surfaces A: Physicochemical and Engineering Aspects, vol. 436, pp. 967-974, 2013.

[22] A. Jorio, M. A. Pimenta, A. G. Souza Filho, R. Saito, G. Dresselhaus, and M. S. Dresselhaus, "Antihelium-3 production in leadlead collisions at $158 \mathrm{~A} \mathrm{GeV/c,"} \mathrm{New} \mathrm{Journal} \mathrm{of} \mathrm{Physics,} \mathrm{vol.} \mathrm{5,} \mathrm{pp.}$ 1-17, 2003.

[23] S. Bose, T. Kuila, A. K. Mishra, R. Rajasekar, N. H. Kim, and J. H. Lee, "Carbon-based nanostructured materials and their composites as supercapacitor electrodes," Journal of Materials Chemistry, vol. 22, no. 3, pp. 767-784, 2012.

[24] D. Antiohos, G. Folkes, P. Sherrell et al., "Compositional effects of PEDOT-PSS/single walled carbon nanotube films on supercapacitor device performance," Journal of Materials Chemistry, vol. 21, no. 40, pp. 15987-15994, 2011.

[25] M. Selvakumar and D. K. Bhat, "Activated carbon-polyethylenedioxythiophene composite electrodes for symmetrical supercapacitors," Journal of Applied Polymer Science, vol. 107, no. 4, pp. 2165-2170, 2008.
[26] J. Wang, Y. Xu, J. Zhu, and P. Ren, "Electrochemical in situ polymerization of reduced graphene oxide/polypyrrole composite with high power density," Journal of Power Sources, vol. 208, pp. 138-143, 2012.

[27] Y. Wu, K. Zhang, J. Xu et al., "Sensitive detection of hydroxylamine on poly(3,4-ethylenedioxythiophene)/graphene oxide nanocomposite electrode," International Journal of Electrochemical Science, vol. 9, no. 11, pp. 6594-6607, 2014.

[28] E. Frackowiak, "Carbon materials for supercapacitor application," Physical Chemistry Chemical Physics, vol. 9, no. 15, pp. 1774-1785, 2007.

[29] H. Pan, J. Li, and Y. P. Feng, "Carbon nanotubes for supercapacitor," Nanoscale Research Letters, vol. 5, no. 3, pp. 654-668, 2010.

[30] T. Zhou, D. Chen, J. Jiu et al., "Electrically conductive bacterial cellulose composite membranes produced by the incorporation of graphite nanoplatelets in pristine bacterial cellulose membranes," Express Polymer Letters, vol. 7, no. 9, pp. 756-766, 2013.

[31] D. Ge, L. Yang, L. Fan et al., "Foldable supercapacitors from triple networks of macroporous cellulose fibers, single-walled carbon nanotubes and polyaniline nanoribbons," Nano Energy, vol. 11, pp. 568-578, 2015.

[32] J.-X. Feng, Q. Li, X.-F. Lu, Y.-X. Tong, and G.-R. Li, "Flexible symmetrical planar supercapacitors based on multi-layered $\mathrm{MnO}_{2} / \mathrm{Ni} /$ graphite/paper electrodes with high-efficient electrochemical energy storage," Journal of Materials Chemistry A, vol. 2, no. 9, pp. 2985-2992, 2014.

[33] T. L. Kelly, K. Yano, and M. O. Wolf, "Supercapacitive properties of PEDOT and carbon colloidal microspheres," ACS Applied Materials and Interfaces, vol. 1, no. 11, pp. 2536-2543, 2009.

[34] D. Shin, Y. Ko, and J. Cho, "Layer-by-layer assembled (highenergy carbon nanotube/conductive carbon nanotube)n nanocomposites for high volumetric capacitance supercapacitor electrodes," RSC Advances, vol. 6, no. 26, pp. 21844-21853, 2016.

[35] R. B. Rakhi, W. Chen, D. Cha, and H. N. Alshareef, "High performance supercapacitors using metal oxide anchored graphene nanosheet electrodes," Journal of Materials Chemistry, vol. 21, no. 40, pp. 16197-16204, 2011.

[36] H. Li, B. Wang, X. He et al., "Composite of hierarchical interpenetrating 3D hollow carbon skeleton from lotus pollen and hexagonal $\mathrm{MnO}_{2}$ nanosheets for high-performance supercapacitors," Journal of Materials Chemistry A, vol. 3, no. 18, pp. 9754-9762, 2015.

[37] X. Wang, K. Gao, Z. Shao, X. Peng, X. Wu, and F. Wang, "Layerby-Layer assembled hybrid multilayer thin film electrodes based on transparent cellulose nanofibers paper for flexible supercapacitors applications," Journal of Power Sources, vol. 249, pp. 148-155, 2014.

[38] L. Lai, H. Yang, L. Wang et al., "Preparation of supercapacitor electrodes through selection of graphene surface functionalities," ACS Nano, vol. 6, no. 7, pp. 5941-5951, 2012.

[39] C. Lei and C. Lekakou, "Carbon-based nanocomposite EDLC supercapacitors," in Proceedings of the Nanotechnology Conference and Expo, vol. 1, pp. 176-179, Anaheim, Calif, USA, June 2010.

[40] K. Xu, X. Huang, Q. Liu et al., "Understanding the effect of polypyrrole and poly(3,4-ethylenedioxythiophene) on enhancing the supercapacitor performance of $\mathrm{NiCo}_{2} \mathrm{O}_{4}$ electrodes," Journal of Materials Chemistry A, vol. 2, no. 39, pp. 16731-16739, 2014. 
[41] S. Li, C. Zhao, K. Shu et al., "Mechanically strong high performance layered polypyrrole nano fibre/graphene film for flexible solid state supercapacitor," Carbon, vol. 79, no. 1, pp. 554-562, 2014.

[42] R. K. Sharma, A. Karakoti, S. Seal, and L. Zhai, "Multiwall carbon nanotube-poly(4-styrenesulfonic acid) supported polypyrrole/manganese oxide nano-composites for high performance electrochemical electrodes," Journal of Power Sources, vol. 195, no. 4, pp. 1256-1262, 2010. 

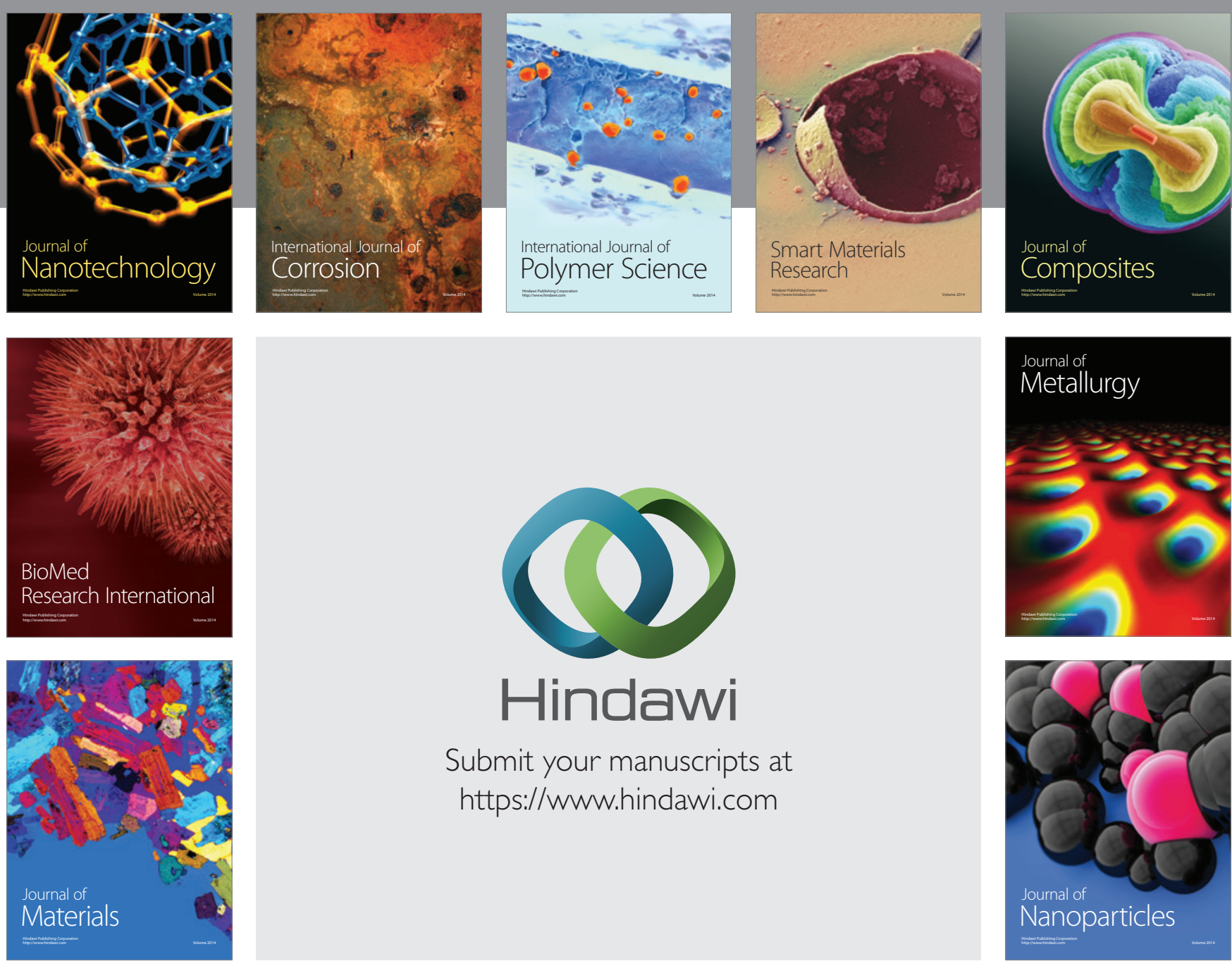

\section{Hindawi}

Submit your manuscripts at

https://www.hindawi.com

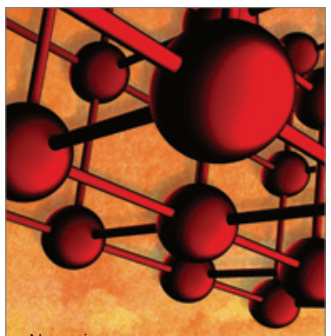

Materials Science and Engineering
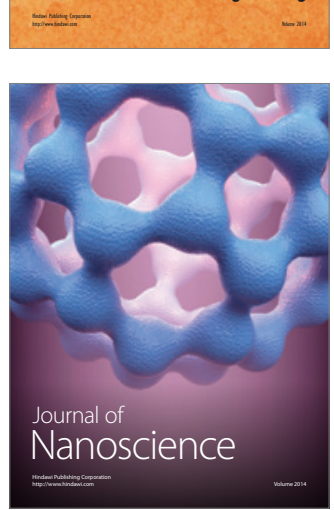
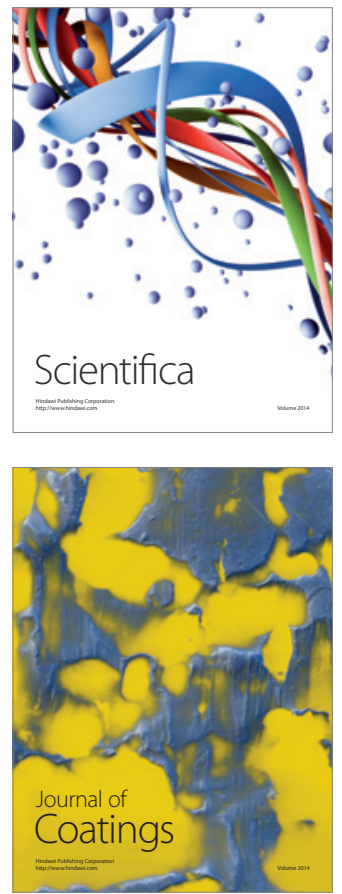
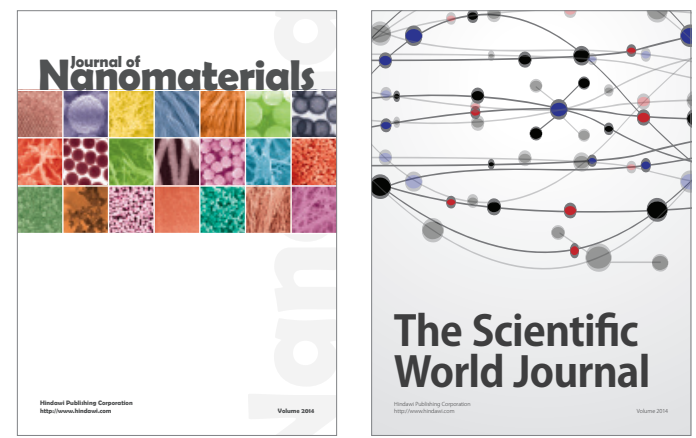

The Scientific World Journal
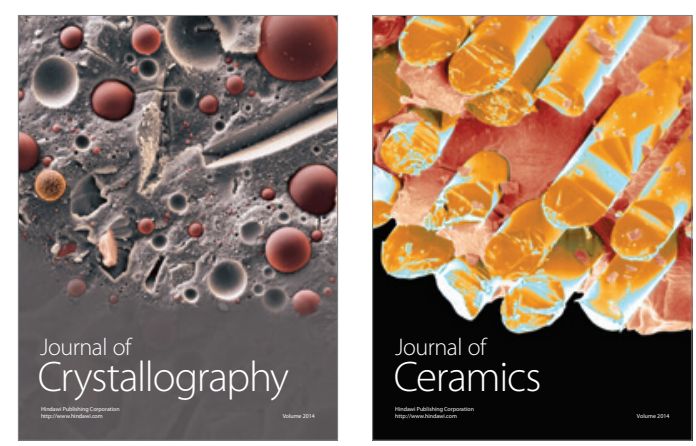
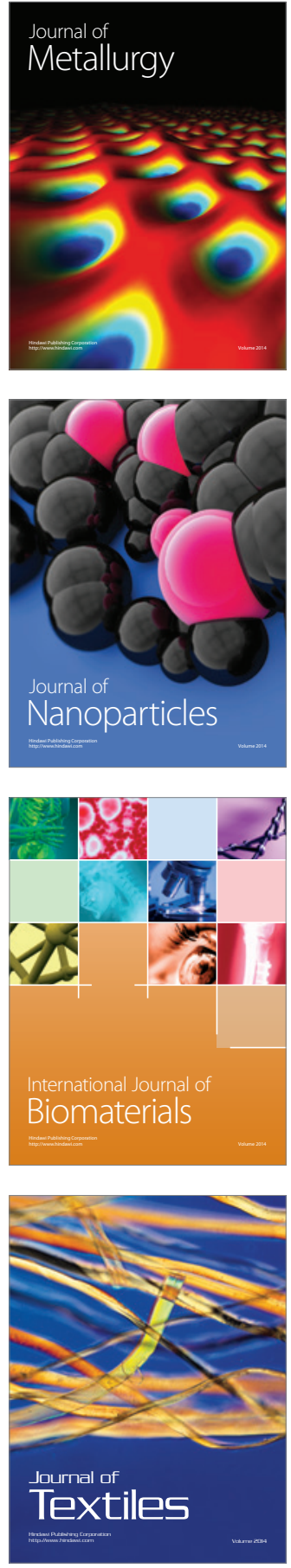